\title{
Clinical Characteristics of Neck Stab Wounds: A Single-Institute Retrospective Study of 89 Patients
}

\author{
Yun Ji Lee, Hyo Jun Kim, Hyun Tag Kang, Seung Won Lee, and Ki Nam Park (D \\ Department of Otorhinolaryngology-Head and Neck Surgery, Soonchunhyang University, Bucheon, Korea
}

\author{
경부 자상의 임상 양상: 단일 기관 후향적 분석 \\ 이윤지 · 김효준 · 강현택 · 이승원 · 박기남 \\ 순천향대학교 의과대학 이비인후-두경부외과학교실
}

\section{Received June 6, 2019}

Revised November 22, 2019

Accepted November 28, 2019

Address for correspondence

Ki Nam Park, MD

Department of Otorhinolaryngology-

Head and Neck Surgery,

Soonchunhyang University,

170 Jomaru-ro, Bucheon 14584,

Korea

Tel $+82-32-621-6582$

Fax $+82-32-621-6950$

E-mail man7140@gmail.com
Background and Objectives Neck stab wounds should be managed properly as they can result in life-threatening complications and death. However, guns are prohibited in South Korea and many previous studies conducted in other countries are thus inapplicable. Also, most of the existing case reports deal mostly with profound neck injury and might lead to misunderstanding regarding the severity of injuries when considering neck stab wounds. This study analyzed the clinical characteristics of neck stab wounds according to the cause of trauma.

Subjects and Method A total of 89 patients with neck stab wounds who visited the emergency room between January 2005 and June 2017 were enrolled. Medical records and radiological findings were reviewed retrospectively. The patients were divided into two groups according to the cause of trauma (suicide attempt or assault by another person). A comparative analysis of the two groups was conducted.

Results The patients consisted of 41 cases of (46.1\%) attempted suicides and 26 cases of $(29.2 \%)$ psychiatric disorders. Of these, more than half had superficial wounds above the platysma, and multiple anatomical lacerations were found in 40 cases $(45 \%)$. Psychiatric diagnoses were identified only in the attempted-suicide group $(p<0.001)$, and injuries to the posterior neck triangle were observed only in the assault-by-another-person group ( $p=0.029)$. There were 11 cases $(12.4 \%)$ of profound injury, but there was no significant difference between the two groups. One patient with injury by another person died due to the cutting of the common carotid artery.

Conclusion Superficial injuries were more common while profound injuries were relatively uncommon in this study. However, physicians should pay attention to proper evaluation and management comprehensively in cases of neck stab wounds.

Korean J Otorhinolaryngol-Head Neck Surg 2021;64(4):247-51

Key Words Neck $\cdot$ Stab wound $\cdot$ Suicide, attempted $\cdot$ Violence.

\section{서 론}

경부는 순환기, 호흡기, 소화기, 내분비 및 근신경 계통의 다양한 중요 구조물이 위치하는 해부학적 부위로 단단한 골 격으로 보호되지 않아 외상 시 심각한 합병증 및 사망을 초

This is an Open Access article distributed under the terms of the Creative Commons Attribution Non-Commercial License (https://creativecommons.org/licenses/by-nc/4.0) which permits unrestricted non-commercial use, distribution, and reproduction in any medium, provided the original work is properly cited.
래할 수 있어 즉각적인 평가와 처치가 필요하다. 경부 관통상 의 경우 0 11\% 정도의 사망률이 보고되고 있으며,1, 기도와 식도 손상이 19\%에서 동반되는 ${ }^{2}$ 심각한 외상 중 하나이다. 다만 이들 외국의 연구들에는 총기로 인한 경부 관통상이 포함되어 있어, 총기 규제 국가인 대한민국에서 경부 손상의 사망률 및 합병증 빈도는 기존 보고와 다를 수 있다. 국내의 경우 경부 외상의 대부분은 경부 자상(stabbing)이 차지하고 있으며, 전세계적으로도 경부 외상 중 가장 흔한 것은 폭행 
으로 인한 경부 자상이다. ${ }^{3}$

국내 경부 자상에 대한 연구들은 식도 및 후두 손상에 대 한 증례 보고들이 대부분으로, ${ }^{4-7)}$ 우리나라 경부 자상의 임 상 양상을 분석한 연구는 전무한 실정이다. 기존 증례 보고 들은 기도나 혈관 등의 주요 장기 손상을 동반하여 치료가 상당히 어려운 경우들을 다루고 있어, 임상 의사들로 하여금 경부 자상의 심각성을 실제에 비해 과장되게 인식시킬 수 있 다. 이와 더불어 자살 시도로 인한 경부 자상에 대해서는 합 병증이 적고 사망은 없었다는 외국의 보고가 있으나, ${ }^{8)}$ 타인 에 의한 경우 임상적 특징이 다를 수 있지만 이에 대한 분석 은 보고된 바 없는 상태이다. 이에 본 연구자들은 응급실로 내원한 경부 자상 환자들의 손상의 심각성과 합병증 유무 등 을 분석하고 자해 여부에 따른 임상 양상의 차이가 있는지 알아보고자 하였다.

\section{대상 및 방법}

2005년 1월 2017년 6월까지 경부 자상으로 응급실에 내원
한 156 명 환자의 의무기록을 후향적으로 분석하였다. 분석에 적합한 의무기록이 존재하고 전산화단층촬영(CT)이 시행되 었으며, 본원에서 치료를 받은 환자를 연구 대상으로 하였다. 의무기록 부재로 연구에 필요한 정보를 얻을 수 없는 경우 (16명) 및 자의에 의한 퇴원(5명)과 타 병원으로 전원(14명)을 한 경우는 연구에서 제외하였다. 또한 외상의 원인이 교통사 고(19명), 추락 및 낙상(8명), 산업 재해(5명)와 같은 자해나 타해가 아닌 다른 원인에 의한 경우는 제외하여 총 89명의 환자가 이번 연구에 포함되었다.

환자의 연령, 성별, 정신과적 병력과 자살 시도 여부를 조 사하였고, 수상 당시 음주 여부를 분석하였다. 내원 당시 기 도 유지 필요성(기관 내 삽관 또는 응급 기관 절개술)과 경부 탐색술(surgical exploration) 시행 여부를 조사하였고, CT 를 통해 수상 부위의 위치와 깊이, 주요 혈관과 신경의 손상 여부를 확인하였다. 또한 손이나 복부 등 동반된 다른 부위 의 손상 및 사망 여부를 분석하였다.

수상의 위치는 흥쇄유돌근(sternocleidomastoid muscle) 의 후연(posterior border)을 기준으로 전내측(anteromedi-
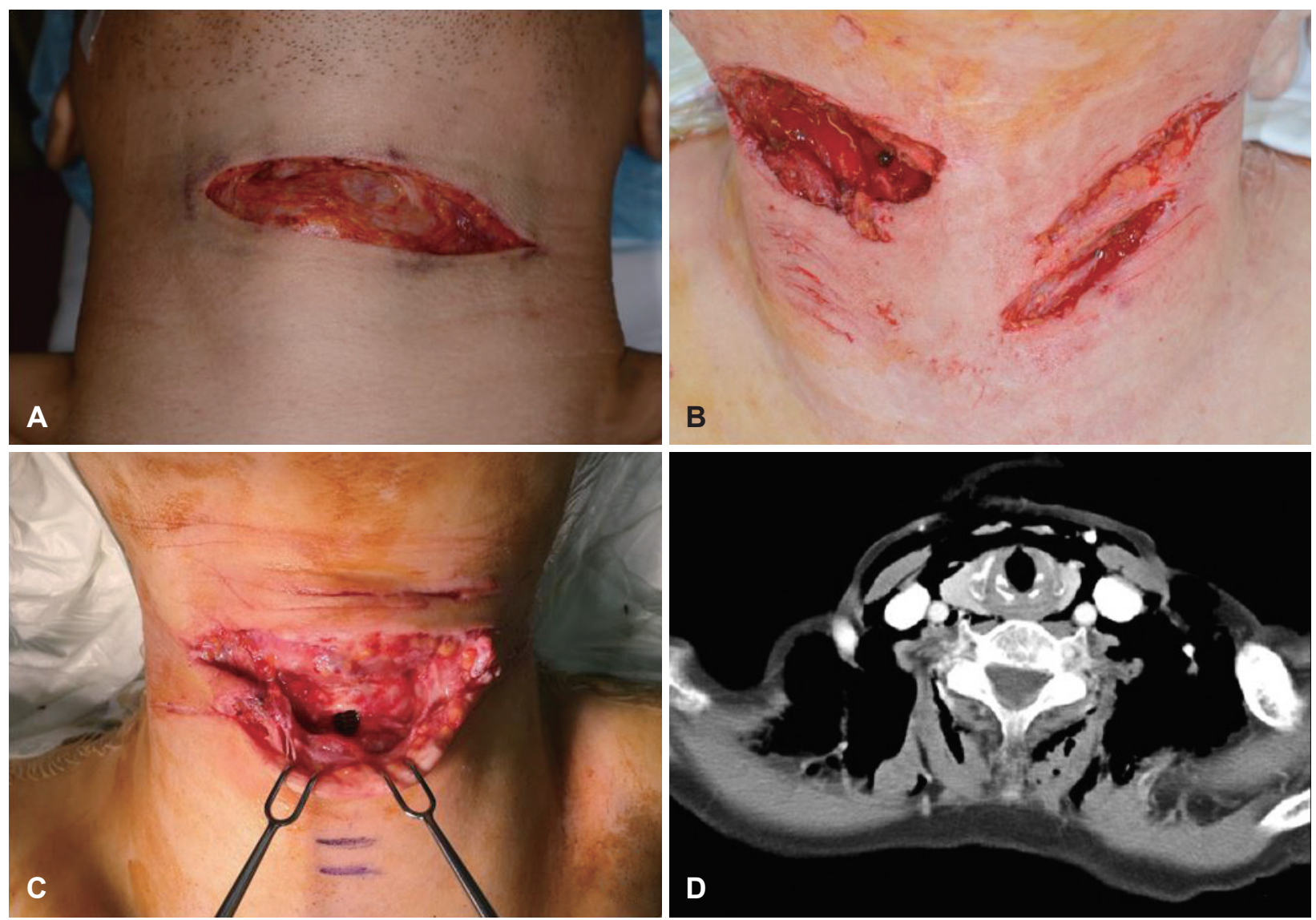

Fig. 1. Neck laceration wounds. The depth of neck laceration was divided into superficial (A) and deep (B) injury based on the platysma. One of the patients showed laryngeal injury (cricothyroid membrane) by suicidal attempt (C). The laryngopharyngeal and esophageal complex injury can cause the massive emphysema in both neck (D). 
al)과 후외측(posterolateral)으로 구분하여 분석하였고, 수 상의 깊이는 활경근(platysma)을 기준으로 나누어 분석(Fig. $1 \mathrm{~A}$ and $\mathrm{B})$ 하였다. 또한 기도와 식도, 내경정맥이나 경동맥 및 그 분지와 같은 주요 혈관과 하부 뇌신경(미주신경, 척수 부신경) 및 상완 신경총 등의 경부 중요 구조물에 손상이 있 는 경우를 중상(profound injury)으로 분류하였다.

연구 대상을 자살 시도 여부에 따라 자해군(attemptedsuicide group, Group A)과 타해군(assault-by-anotherperson group, Group B)으로 나누어, 성별이나 연령 등의 임 상적 특성과 수상 정도, 사망 여부 및 다른 부위 손상 유무 등을 비교 분석하였다.

임상적 특징과 수상의 특징 및 사망 여부에 대해 Student t-test와 chi-square 검정을 이용하여 통계적 분석을 시행하 였고, SPSS(version 18.0 for windows; SPSS Inc., Chicago, $\mathrm{IL}, \mathrm{USA}$ )를 사용하여 유의 수준이 0.05 미만인 경우를 통계 학적으로 유의한 것으로 판정하였다. 본 연구는 인증된 연구 윤리 심의 위원회(Institutional Review Board, IRB)의 승인 을 받았다(IRB No. 2019-03-027).

\section{결 과}

총 89 명의 환자 중 자살 시도로 인한 경부 자상인 경우는 41 명(46.1\%)이었다. 평균 연령은 40.4 \pm 15.7 세, 남성이 56명(62.9\%) 이었다. 응급실 방문 당시 32명(36.0\%)이 주취 상태였고, 26명 (29.2\%)에서 과거 정신과 진료 병력이 확인되었다. 정신과적 병력은 우울증이 17명으로 가장 많았고, 알코올 중독 3 명, 조 현병 2 명 등이었다. 응급실에서 기관 내 삽관이 필요한 경우 는 7명(7.8\%), 응급 기관 절개술이 필요했던 경우는 4명(4.5\%) 였으며, 단순 봉합이 아닌 경부 탐색술이 필요한 경우는 32명 (36.0\%), 다발성 손상은 40명(44.9\%)에서 관찰되었다. 다발성 손상 중 손목 부위가 20명(55\%)으로 가장 많았고, 흥부 5명, 복부 3 명 등이었다. 손상의 위치는 흥쇄유돌근의 전내측이 83명(93.3\%)이었고, 깊이는 50명(56.2\%)에서 활경근보다 얕 은 손상이 있었다. 사망은 1명에서 발생하였다(Table 1). 모든 환자에서 수상의 깊이 및 혈관 손상 등의 합병증 평가를 위 해 경부 $\mathrm{CT}$ 를 시행하였고, 호흡, 소화기계 손상이 의심되거 나 피하 기종(subcutaneous emphysema)이 관찰되는 경우 흥부 CT를 추가로 확인하였다.

중상(profound injury)은 총 11명에서 발생하였다. 호흡, 소화기계 손상은 3 명에서 동반되었고, 후두 손상(Fig. 1C), 기관 손상, 기도와 식도 동시 손상(Fig. 1D)이 각각 1명씩 확 인되었다. 호흡, 소화기계 손상은 기관 절개술, 경부 탐색술 등의 수술로 합병증 없이 회복되었다. 주요 혈관 손상은 5 명
Table 1. Patient demographics and clinical characteristics

\begin{tabular}{lc}
\hline & Total $(\mathrm{n}=89)$ \\
\hline Age & $40.4 \pm 15.7$ \\
Gender & \\
$\quad$ Male & $56(62.9)$ \\
Female & $33(37.1)$ \\
Suicidal attempt & $41(46.1)$ \\
Drunken state & $32(36.0)$ \\
Psychiatric disorders & $26(29.2)$ \\
Imaging work up & \\
$\quad$ Neck CT & $89(100)$ \\
Chest CT & $5(5.6)$ \\
Intubation at emergency room & $7(7.8)$ \\
Emergent tracheostomy & $4(4.5)$ \\
Surgical exploration & $32(36.0)$ \\
Multiple trauma & $40(44.9)$ \\
Location & \\
Anteromedial & $83(93.3)$ \\
Posterolateral & $6(6.7)$ \\
Depth* & \\
Superficial & $50(56.2)$ \\
Deep & $39(43.8)$ \\
Aerodigestive tract damage & $3(3.4)$ \\
Nerve damage & $3(3.4)$ \\
Death & $5(5.6)$ \\
\hline Dascular injury & $1(1.1)$ \\
\hline
\end{tabular}

Data are presented as mean \pm standard deviation or $\mathrm{n}(\%) . *$ depth of the neck laceration wound was divided into superficial and deep based on the platysma

에서 동반되었고, 3 명에서 경정맥 부분 파열, 1 명에서 상갑상 동맥 파열, 1 명에서 경동맥 절단이 확인되었다. 경정맥과 상 갑상동맥 파열은 출혈 부위 결찰로 회복되었으나, 경동맥이 절단된 1명은 수술실에서 사망하였다. 신경 손상은 3 명에서 발생하였는데, 미주신경 손상이 2명이었으며 미주신경과 상 완신경총 동시 손상이 1명이었다. 미주신경 손상 환자는 동 측 성대마비가 발생하였고, 상완신경총 손상 환자는 신경 단 단문합술을 시행하였으나 어깨 운동 장애 및 만성 통증을 호소하였다.

자살 시도 여부를 기준으로 자해군(Group A)과 타해군 (Group B)으로 나누어 분석하였을 때, 연령이나 성별 및 내 원 당시 음주 여부는 두 군 간의 유의한 차이를 보이지 않았 고(Table 2), 흥부 CT 촬영 여부도 군별 차이를 보이지 않았 다. 또한 응급 기관 절개술과 기관 내 삽관 필요 여부도 통계 적으로 유의한 차이를 보이지 않았으며, 경부 이외에 혈관, 신경 및 호흡, 소화기계 손상도 두 군에서 유의한 차이를 보 이지 않았다. 다만, 정신과적 병력 동반 여부는 자해군에서 26 명(63.4\%)으로 타해군에 비해 높았고 $(p<0.001)$, 수상 부위 
Table 2. Comparison according to suicidal attempt

\begin{tabular}{|c|c|c|c|}
\hline & $\begin{array}{c}\text { Group A* } \\
(n=41)\end{array}$ & $\begin{array}{c}\text { Group } B^{\dagger} \\
(n=48)\end{array}$ & $\begin{array}{c}p- \\
\text { value }\end{array}$ \\
\hline Age & \multicolumn{2}{|c|}{$43.9 \pm 14.237 .5 \pm 16.5$} & 0.055 \\
\hline \multicolumn{4}{|l|}{ Gender } \\
\hline Male & $26(63.4)$ & $30(62.5)$ & 0.929 \\
\hline Female & $15(36.6)$ & $18(37.5)$ & \\
\hline Drunken state & $14(34.1)$ & $18(37.5)$ & 0.826 \\
\hline Psychiatric disorders & $26(63.4)$ & $0(0)$ & $<0.001$ \\
\hline Intubation at emergency room & $5(12.2)$ & $2(4.2)$ & 0.085 \\
\hline Emergent tracheostomy & $3(7.3)$ & $1(2.1)$ & 0.235 \\
\hline Surgical exploration & $15(36.6)$ & $17(35.4)$ & 0.909 \\
\hline Multiple trauma & $18(43.9)$ & $22(45.8)$ & 0.855 \\
\hline \multicolumn{4}{|l|}{ Location } \\
\hline Anteromedial & $41(100.0)$ & $42(87.5)$ & 0.019 \\
\hline Posterolateral & $0(0)$ & $6(12.5)$ & \\
\hline \multicolumn{4}{|l|}{ Depth ${ }^{\ddagger}$} \\
\hline Superficial & $23(56.1)$ & $27(56.2)$ & 0.988 \\
\hline Deep & $18(43.9)$ & $21(43.8)$ & \\
\hline Aerodigestive tract damage & $2(4.9)$ & $1(2.1)$ & 0.467 \\
\hline Nerve damage & $1(2.4)$ & $2(4.2)$ & 0.653 \\
\hline Vascular damage & $2(4.9)$ & $3(6.3)$ & 0.779 \\
\hline Death & $0(0)$ & $1(2.1)$ & 0.353 \\
\hline
\end{tabular}

Data are presented as mean \pm standard deviation or $\mathrm{n}(\%)$. *attempted-suicide group, 'assault-by-another-person group, ‡depth of the neck laceration wound was divided into superficial and deep based on the platysma

도 자해군은 모두 흥쇄유돌근의 전내측인데 반해, 타해군에 서는 후측방인 경우가 6명 관찰되어 통계적으로 유의한 차이 가 있었다 $(p=0.019)$. 사망은 타해군에서만 1 명 발생하였으나, 통계적 유의성에 도달하지는 못하였다.

\section{고 찰}

자살을 시도하는 방법의 경우 남성이 여성에 비해 자상이 나 질식 등의 더 공격적인 방법을 사용한다고 알려져 있고, ${ }^{9}$ 경부 자상의 경우도 여성보다 남성의 빈도가 높다고 보고되 어 있다. ${ }^{8,10)}$ 본 연구에서도 마찬가지로 자해군에서 남성 비율 이 $63.4 \%$ 로 높았고, 또한 타해군에서도 같은 결과를 보여 전 체적으로 남성의 빈도가 높게 나타났다.

자살 시도 당시 음주를 한 경우가 $48.2 \%$ 였다는 기존 국내 보고에 비해 ${ }^{11)}$ 본 연구에서는 자해군에서 $34.1 \%$ 로 낮게 나타 났으나, 이는 표본 수의 차이, 의무기록의 충실도 등의 인자 로 과소평가되었을 가능성이 있다. 타해군에서는 신체 손상 환자 중 알코올 의존자와 문제 음주자가 차지하는 비율이 $36 \%$ 였다고 보고한 국내 연구 및 약 20 50\%에 해당하였다 고 보고한 국외 연구들과 일치하는 결과를 보였다. ${ }^{12)}$
독일에서 발표된 연구에서는 $3.7 \%$ 의 경부 자상 환자에서 정신과적 과거력이 확인되었다는 보고 ${ }^{10)}$ 가 있었으나, 스위스 의 연구에서는 $91.7 \%$ 의 높은 빈도로 정신과적 병력을 가진 다고 보고하였다. ${ }^{8)}$ 본 연구에서는 자해군의 경우 정신과적 과거력이 $63.4 \%$ 에서 확인되었는데, 이는 응급 상황에서 자세 한 병력 청취의 어려움으로 상대적으로 낮게 조사되었을 가 능성이 있다.

응급 기도 확보가 필요했던 경우는 타해군에서 $6.3 \%$ 이었 고, 자해군에서는 $19.5 \%$ 로 상대적으로 타해군에서 더 높은 비율을 보였으나 통계학적으로 유의하지는 않았다 $(p=0.058)$. 경부 관통상의 50 80\%가 윤상연골에서 하악골각까지에 해 당하는 Zone II에서 발생하고, ${ }^{13)}$ 자살 시도가 원인인 경우 모 든 환자에서 Zone II의 상해가 발생하였다는 이전의 보고들 을 참고하였을 때, ${ }^{8)}$ 자해에 의한 경부 자상 환자에서 타해에 의한 경우보다 응급 기도 확보를 요하는 사례가 더 많을 것 으로 예측된다.

경부 관통상(penetrating neck trauma)은 활경근 심부의 수 상으로서 전통적으로 수상 부위에 따라서 세 가지 부위(zone) 로 나누어 접근을 하였다. ${ }^{14)}$ 하지만 최근 쇼크나 박동성 혈종, 기도 폐쇄 등의 징후와 CT를 통한 주요 구조물의 손상 감별 로 불필요한 경부 탐색술을 줄일 수 있다는 'no zone' 접근법이 제시되고 있다. ${ }^{15)}$ 본 연구 결과에서 전체 경부 자상 중 $56.2 \%$ 가 활경근의 표재성 손상이었고, 나머지 심부 손상 환자들을 구 역에 따라 분석하였을 때 구역에 따른 차이는 통계적으로 유 의한 차이를 보이지 않아 결과에 표기하지 않았다. 아울러 두 군에서 표재성 손상 빈도의 차이를 보이지 않아, 이는 수 상의 원인이 손상의 깊이 정도를 예측하는 인자로 활용될 수 없다는 것을 의미한다.

수상 위치의 경우 타해군에서만 경부의 후외측 삼각에 발 생하여, 자상이 흥쇄유돌근 후연의 후외측에 위치한 경우 자 해 보다는 타인에 의한 수상의 가능성이 높음을 알 수 있다. 또한 상완신경총 손상이 후외측 삼각 자상 1 명에서 발생하 여, 환자 평가 시에 해당 부위 자상 환자의 경우 팔의 감각이 나 운동에 대한 신경학적 평가가 특히 필요함을 주지하여야 하겠다.

경부 탐색술(surgical exploration)이 필요했던 경우는 $36 \%$ 로, 주로 출혈이 많거나 수상 깊이가 흉쇄유돌근을 관통한 경우에서 주요 구조물의 손상 확인이 필요하여 시행되었고, 자살 시도 여부에 따른 빈도 차이는 없었다. 경부 관통상의 84.4\%에서 경부 탐색술이 필요하였다는 이전 연구 ${ }^{16)}$ 에 비해서 는 본 연구의 빈도가 낮게 나타났으나 이는 경부 총상이 포함 된 연구이므로 직접 비교는 어려울 것으로 판단된다. 브라질 에서 시행한 한 연구 결과에 따르면 경부 관통상의 $40 \%$ 에서 
선택적으로 경부 탐색술(surgical exploration)이 필요하였다 고 보고하여 본 연구와 유사한 결과를 보였다. ${ }^{17)}$

중상(profound injury)은 3 5\% 정도로 기존 연구에 비해 ${ }^{8)}$ 낮은 빈도를 보였고, 사망의 경우 타해군에서만 1 명 발생하 여 두 군 간의 차이는 통계학적인 유의성에 도달하지 못하였 다. 이는 자살 시도로 생긴 깊은 경부 자상으로 인해 사망한 경우는 없었다는 이전의 보고와 일치하는 결과이다. ${ }^{8)}$ 과거 경부 관통상 연구에서 사망률을 3 6\%로 보고하였으나, ${ }^{18)}$ 본 연구에서는 $2.1 \%$ 의 낮은 비율로 나타났다. 그러나 본 연구는 표층 손상이 연구에 포함되고 권총상을 연구 대상에 포함하

지 않기 때문에 직접적인 비교는 어렵다.

본 연구는 의무기록의 후향적 분석으로 인한 선택 오류, 의 무기록 충실도 문제와 단일 기관 분석으로 인한 적은 표본 수를 제한점으로 가진다. 하지만, 대부분의 경부 자상에 대한 연구는 증례 분석 수준에서 이루어지고 있어 경부 자상을 원 인에 따라 분석한 첫 국내 연구로서 의의가 있다. 또한 추가 연구를 통해 보다 의미 있는 결과를 도출할 수 있을 것으로 기대한다.

경부 자상을 주소로 응급실에 환자가 내원한 경우 절반 이 상이 표재성 손상이며, 중상의 빈도가 낮아 응급 경부 탐색 술 등의 초응급 처치가 필요한 경우는 다소 심각한 고려 대 상이 아닐 것으로 판단된다. 그러나 경부에 대한 자세한 이 학적 검사와 영상의학적 검사를 통한 평가를 소홀히 해선 안 된다. 또한 다발성 손상을 비교적 흔하게 동반하므로 타 장 기 손상 여부를 항상 확인하고 이에 맞는 적극적인 타 과 협 진을 시행하여야 하며, 특히 자해의 경우 정신건강의학과와 의 협업 및 재발 방지 등을 위한 추적 관찰이 필요할 것이다.

\section{Acknowledgments}

This work was supported by Soonchunhyang University Research Fund.

\section{Author Contribution}

Conceptualization: Ki Nam Park. Data curation: Yun Ji Lee, Hyun Tag Kang, Seung Won Lee. Formal analysis: Hyo Jun Kim, Hyun Tag Kang, Ki Nam Park. Funding acquisition: Seung Won Lee. Investigation: Hyo Jun Kim. Methodology: Hyo Jun Kim. Resources: Seung Won Lee. Supervision: Seung Won Lee. Writing_original draft: Yun Ji Lee. Writing—review \& editing: Ki Nam Park.

\section{ORCID}

Ki Nam Park

https://orcid.org/0000-0001-6641-3981

\section{REFERENCES}

1) Britt LD, Peyser MD. Penetrating and blunt neck trauma. In: Mattox KL, Feliciano DV, Moore EE, editors. Trauma. 4th ed. New York, NY: McGraw-Hill;2000. p.437-50.

2) Grewal H, Rao PM, Mukerji S, Ivatury RR. Management of penetrating laryngotracheal injuries. Head Neck 1995;17(6):494-502.

3) Burgess CA, Dale OT, Almeyda R, Corbridge RJ. An evidence based review of the assessment and management of penetrating neck trauma. Clin Otolaryngol 2012;37(1):44-52.

4) Kim EH, Lee GH, Koo BS, Yoon YH. CSF leak and pneumocephalus caused by neck stab wound. Korean J Otorhinolaryngol-Head Neck Surg 2009;52(6):522-4.

5) Kim YH, Choi JS, Kang SH, Yu MS. Penetrating neck laceation with epiglottis amputation which was successfully repaired. Korean J Otorhinolaryngol-Head Neck Surg 2012;55(6):369-72.

6) Bhatt NR, McMonagle M. Penetrating neck injury from a screwdriver: Can the no zone approach be applied to zone i injuries? BMJ Case Rep 2015;2015:bcr2015212666.

7) Lee HK, Woo SH, Choi DS, Kim JP. A case of the zone III penetrating neck injury with internal carotid artery laceration treated by an urgent endovascular stent technique. Korean J Otorhinolaryngol-Head Neck Surg 2010;53(4):236-40.

8) Biétry D, Exadaktylos A, Müller T, Zbären P, Caversaccio M, Arnold A. Sharp neck injuries in suicidal intention. Eur Arch Otorhinolaryngol 2015;272(12):3825-31.

9) Ventrice D, Valach L, Reisch T, Michel K. Suicide attempters' memory traces of exposure to suicidal behavior: A qualitative pilot study. Crisis 2010;31(2):93-9.

10) Herzog M, Hoppe F, Baier G, Dieler R. [Injuries of the head and neck in suicidal intention]. Laryngorhinootologie 2005;84(3):176-81.

11) Lim MR, Lee SJ, Park J-I. Characteristics of Korean suicide attempters. J Korean Neuropsychiatr Assoc 2015;54(2):209-15.

12) Lee WK, Kim Y. Drinking pattern and nonfatal injuries of adults in Korea. J Korean Soc Traumatol 2009;22(2):233-41.

13) Nason RW, Assuras GN, Gray PR, Lipschitz J, Burns CM. Penetrating neck injuries: Analysis of experience from a Canadian trauma centre. Can J Surg 2001;44(2):122-6.

14) Roon AJ, Christensen N. Evaluation and treatment of penetrating cervical injuries. J Trauma 1979;19(6):391-7.

15) Ibraheem K, Khan M, Rhee P, Azim A, O'Keeffe T, Tang A, et al. "No zone" approach in penetrating neck trauma reduces unnecessary computed tomography angiography and negative explorations. J Surg Res 2018;221:113-120.

16) Mahmoodie M, Sanei B, Moazeni-Bistgani M, Namgar M. Penetrating neck trauma: Review of 192 cases. Arch Trauma Res 2012;1(1):14-8.

17) Teixeira F, Menegozzo CA, Netto SD, Poggeti RS, Collet E Silva Fde S, Birolini D, et al. Safety in selective surgical exploration in penetrating neck trauma. World J Emerg Surg 2016;11:32.

18) McConnell DB, Trunkey DD. Management of penetrating trauma to the neck. Adv Surg 1994;27:97-127. 